University of Nebraska - Lincoln DigitalCommons@University of Nebraska - Lincoln

School of Accountancy Publications

Accountancy, School of

2011

\title{
An Evidential Reasoning Approach to Fraud Risk Assessment under Dempster-Shafer Theory: A General Framework
}

\section{Lei Gao}

University of Nebraska - Lincoln, lgao3@unl.edu

Theodore J. Mock

University of California, Riverside, tmock@ucr.edu

Rajendra P. Srivastava

University of Kansas, rsrivastava@ku.edu

Follow this and additional works at: http://digitalcommons.unl.edu/acctpubs

Part of the Accounting Commons

Gao, Lei; Mock, Theodore J.; and Srivastava, Rajendra P., "An Evidential Reasoning Approach to Fraud Risk Assessment under Dempster-Shafer Theory: A General Framework" (2011). School of Accountancy Publications. 1.

http://digitalcommons.unl.edu/acctpubs/1

This Article is brought to you for free and open access by the Accountancy, School of at DigitalCommons@University of Nebraska - Lincoln. It has been accepted for inclusion in School of Accountancy Publications by an authorized administrator of DigitalCommons@University of Nebraska Lincoln. 


\section{An Evidential Reasoning Approach to Fraud Risk Assessment under Dempster-Shafer Theory: A General Framework}

\author{
Lei Gao \\ University of Nebraska-Lincoln \\ Email:1gao3@unl.edu
}

\author{
Theodore J. Mock \\ University of California-Riverside \\ Email: tmock@ucr.edu
}

\author{
Rajendra P. Srivastava \\ University of Kansas \\ Email: rsrivastava@ku.edu
}

\begin{abstract}
This paper develops a general framework under Dempster-Shafer theory for assessing fraud risk in a financial statement audit by integrating the evidence pertaining to the presence of fraud triangle factors (incentives, attitude and opportunities), and evidence concerning both account-based and evidence-based fraud schemes. This framework extends fraud risk assessment models in prior research in three respects. 1) It integrates fraud schemes, both account schemes through which accounts are manipulated, and evidence schemes through which frauds are concealed, into a single framework. 2) It incorporates prior fraud frequency information obtained from the Accounting and Auditing Enforcement Releases issued by the Securities and Exchange Commission into an evidential network which uses Conditional OR relationships among assertions. 3) The framework provides a structured approach for connecting risk assessment, audit planning, and evaluation of audit results. The paper uses a real fraud case to illustrate the application of the framework.
\end{abstract}

\section{Introduction}

The main objective of this paper is to develop a general framework for assessing the risk of fraud committed by management in reporting the financial performance of a company using the evidential reasoning approach under Dempster-Shafer (DS) theory of belief functions. In more specific terms, the objective of the paper is to develop a general framework for assessing fraud risk using an evidential reasoning approach by integrating fraud triangle factors (Incentives, Attitude, and Opportunities which must be present for management to commit fraud) with fraud schemes (schemes through which management perpetrates fraud). In addition, this study incorporates both the account-based fraud schemes and evidencebased fraud schemes into the fraud risk assessment framework. Account-based fraud schemes are used by management to manipulate account balances, while evidence-based fraud schemes are used to deceive auditors and conceal fraud [11] by creating bogus evidence or manipulating evidence by colluding with customers. In addition, the framework integrates frequency information of fraud schemes obtained from previous fraud cases disclosed by the SEC to help improve the efficiency and effectiveness of fraud detection.

In recent years, management fraud has drawn heightened attention from all sectors of the economy due to the occurrence of fraud in several major public companies [20,43].. Simultaneously, the American Institute of Certified Public Accountants released SAS 99 [2] to replace SAS 82 [1] on consideration of fraud in financial statement audits. The new standard emphasizes the importance of evaluating fraud risk from the view of the three fraud triangle factors and the use of brainstorming sessions to assess fraud risk and evaluate how fraud could be perpetrated. However, SAS 99 does not provide detailed guidance on how auditors should consider fraud schemes in risk assessment or how auditors should adjust audit programs to respond to the assessed fraud risk.

The present study uses a real fraud case to illustrate the application of the framework and demonstrates how to make preliminary fraud risk assessments, how to plan audit programs, how to aggregate and evaluate audit evidence, and how to make a final assessment of fraud risk.

The rest of this paper is organized as follows. Section 2 reviews prior literature. Section 3 presents a general evidential reasoning framework for fraud risk assessment. Section 4 uses a real fraud case to illustrate how auditors may use evidential diagrams to perform fraud risk assessment, to plan audit programs, and to evaluate audit results. Section 5 concludes with a discussion of contributions and future research.

\section{Prior research}

Since this paper deals with both the application of an evidential reasoning approach under DS theory and the fraud risk assessment process, we provide a brief literature review in both areas. The evidential reasoning approach presented is a structured approach where decisions are made based on the evidence available and uncertainties in the evidence are modeled using DS theory [16]. This approach has been used in many disciplines from multiple-attribute decision making with uncertainty $[43,44]$ to information security [38] and WebTrust services [34]. Srivastava and his co-authors have applied this approach to auditing and assurance services [18, 31, $37]$. We apply this approach to assess the risk of fraud committed by management. 
Prior studies on fraud risk assessment focus largely on using fraud risk factors and "red flags" to assess the overall risk of fraudulent financial reporting. In this approach, which has been adopted in SAS 99 [2], the auditor identifies the presence of red flags and then assesses the risk of fraud $[5 ; 8,9,23]$.

To facilitate the use of red flags, various decision aids have been developed including checklists, regression models and expert systems. Although the checklist is the most common decision aid, it may be ineffective [23]. Prior research finds that regression models perform better than a simple checklist and that expert systems perform better than either checklists or regression models $[5 ; 8]$. One potential limitation of such approaches is that they assess fraud risk without considering the impact of evidence concerning fraud schemes which are used by management to perpetrate and conceal fraud.

Prior fraud research using other approaches such as neural network [13] and strategic auditing where the audit process is treated as if it were a game, with auditors and management functioning as the players $[6,21]$ are also restricted to the assessment of fraud risk without considering the impact of fraud schemes. Thus, even if the auditor correctly identifies a high-fraud-risk situation, the auditor may not design effective fraud detection procedures because he or she is misled by manipulated evidence provided by management. It may be helpful for auditors to consider how fraud can be perpetrated and concealed. To consider this possibility, this study integrates the assessment and tests of fraud schemes into the process of fraud risk assessment with the objective of improving effectiveness of fraud detection.

As mentioned earlier, the proposed framework uses the DS Theory of Belief Functions as the formalism for defining and managing uncertainties involved in the audit evidence. Several studies suggest that Belief Functions provide a useful framework for mapping uncertainties and ambiguity in the audit judgment process $[7,14,26]$. We assume that readers have a basic understanding of DS theory and thus do not provide an introduction to the theory. However, for a detailed introduction, we encourage readers to see [29, $33,37]$.

\section{A general evidential diagram for fraud risk assessment}

This paper uses an evidential reasoning approach to develop a framework for assessing fraud risk and to facilitate audit planning. Under this approach, an auditor assesses the status of assertions based on partial knowledge about a variable of interest such as a material account balance in the financial statement and knowledge about other variables or assertions that are related to the particular account balance variable [22. 39].

Figure 1 presents a general evidential diagram for assessing fraud risk. The oval-shaped boxes represent assertions and sub-assertions, the rectangular boxes represent items of audit evidence, and circles represent relational nodes connected to assertions and subassertions. Dotted lines are used to represent those assertions or items of evidence that could have been connected to related assertions but were omitted in the diagram for simplification. As constructed, Figure 1 indicates that the assessment as to whether fraud is present in Account A depends on five general types of evidence: results of analytical procedures, the evaluation of the fraud triangle factors, evidence about general account schemes and specific account schemes, and evidence about specific evidence schemes.

At the left is the main variable being investigated, specifically whether material fraud is or is not present in a particular financial account. This variable is evaluated in the form of an assertion - fraud is present in Account A. The expectation in most audits is that collected audit evidence will disconfirm this assertion. The assertion nodes include different levels of assertions where sub-assertions are connected to the main assertion through relational nodes. In Figure 1, all relationships are assumed to be 'Conditional OR' or 'CR'. Srivastava, Gao, and Gillett [32] have modeled "Conditional OR (CR)" under DS theory for propagating beliefs in a network of variables. Under this relationship, the sub-assertions in a network of variables are related to the main assertion through "OR" logic, i.e., if any of the sub-assertions is true then the main assertion is true. In the case of fraud, this is the logical relationship between the various fraud schemes and the main fraud objective. That is, fraud will occur if any of the fraud schemes such as the recording of fictitious revenues are evident.

However, the reverse relationship is conditioned upon historical frequency evidence. For example, if fraud is suspected, i.e., there is evidence that fraud has occurred but where it has occurred may not be known; it may depend upon the most likely fraud schemes that management in the past has found easy to perpetrate and conceal it from the auditor. Evidence nodes (the rectangular nodes) provide the evidence that the auditor collects to assess the level of support in favor of or against the corresponding assertions or subassertions.

Under the belief-function framework, items of audit evidence are combined using Dempster's rule [25]. We use the Shenoy and Shafer [27] "local computation" technique for propagating beliefs at each assertion and sub-assertion in the evidential diagram to determine the overall belief at each node in the network.

In Figure 1 there are three levels of sub-assertions beyond the main assertion. The first level indicates the general account schemes that have been used to commit fraud. The second assertion level indicates the specific account schemes that have been used and the third assertion level identifies specific evidence schemes used to conceal fraud.

\section{Use of evidential reasoning approach in fraud risk assessment}

Having completed the evidential diagram, the next 
step is to gather relevant evidence pertaining to various assertions and sub-assertions to determine the overall belief and plausibility whether the main assertion is true, i.e., fraud is present in account A.

Under DS theory, the belief in fraud, Bel(fraud), represents the total belief that fraud is present based on the evidence. Bel(fraud) $=0$ implies that we have no evidence indicating that there is fraud. Also, Bel(no fraud $)=0$ implies that we have no evidence that there is 'no fraud'; a situation of complete ignorance with respect to the assertions being investigated. This may be the situation when the auditor starts an audit engagement for a new client; the auditor lacks evidence in favor or in negation of assertions being true. However, under the complete ignorance situation the plausibility of fraud being present and not being present is 1 , that is $\mathrm{Pl}($ fraud $)=1$ and $\mathrm{Pl}($ no fraud $)=1$.

Consider another situation where the auditor has very weak evidence that fraud is present, say at a belief of 0.01 on a scale of $0-1$, that is $\operatorname{Bel}($ fraud $)=0.01$, and moderately strong evidence that fraud is not present say at a belief of 0.6 , that is $\operatorname{Bel}($ no fraud) $=0.6$. We assume these belief values are based on the available audit evidence. We provide several examples of such items of evidence in Section 5.

Since $\mathrm{Pl}(\mathrm{A})=1-\operatorname{Bel}($ not $\mathrm{A})$, given the above values, $\mathrm{Pl}($ fraud $)=0.4$ and $\mathrm{Pl}($ no fraud $)=0.99$. Note that while the evidence suggests that fraud is not present with a belief of 0.6 , it is plausible with degree 0.99 that there is no fraud. Similarly, the evidence suggests that fraud is present with 0.01 belief, that is, the auditor has direct evidence that fraud is present with a low level of belief 0.01 , while it is plausible that fraud could be present with 0.4 degree on a scale of $0-1$.

The above situation might arise when the auditor identifies discrepancies in accounting records or conflicting or missing evidential matter [2]. Based on just this evidence, fraud is possible, although with only a belief of 0.01 , but with a plausibility of 0.4 .

Next, we discuss how the assessed belief in fraud and fraud risk should impact the audit process in terms of further evidence collection. As the audit team is investigating fraud risk, a strategy needs to be selected concerning whether additional evidence needs to be collected or whether this particular phase of the audit is complete (that is, whether sufficient, competent evidence has been obtained in order to reach a conclusion). For the above situation where the plausibility of fraud is 0.4 , an appropriate strategy for a skeptical auditor would be to investigate further until either the additional evidence reduces the plausibility of fraud, i.e., the fraud risk, to a much lower level or indicates that belief in fraud surpasses a threshold, say 0.10 . The plausibility of fraud, $\mathrm{Pl}$ (fraud), can be interpreted as fraud risk under DS theory. This interpretation is similar to the definition of audit risk as suggested by Srivastava and Shafer [38].

In general, the objective of an audit of financial statements is to determine, with reasonable assurance, whether the financial statements are free from material misstatements due to error or fraud. The auditor issues an unqualified opinion if there is sufficient and competent evidence that provide reasonable assurance that the financial statements are free from material misstatements due to error or fraud.

If plausibility is used as the benchmark for fraud risk, this means that the auditor must have a reasonably high level of belief, say 0.95 , that there is 'no fraud' in the financial statements in order to give an unqualified opinion. This implies that, for an unqualified opinion, the plausibility that there is 'fraud' in the financial statements has to be reasonably low, say 0.05 . Plausibility will be equal to 0.05 if the belief in 'no fraud' is 0.95 , even though there may be no or little evidence that fraud is present.

In Section 5, we demonstrate how items of evidence can be combined with frequency information of fraud schemes to determine the overall belief in fraud, the overall belief in no fraud and the plausibility of fraud.

\section{An illustration of assessing belief in fraud and fraud risk}

To illustrate how auditors may use the evidential diagram to assess fraud risk and plan audit programs, a fraud case disclosed in AAERs by the SEC [40-43] is used. The fraud was committed by the management of FLIR Systems, Inc. (FLIR), a listed company designing and manufacturing thermal imaging and broadcast camera systems that detect infrared radiation. According to the SEC's releases, FLIR engaged in a wide range of schemes to inflate revenue and earnings in 1998 and 1999.

FLIR began its improper revenue recognition in the first quarter of 1998 and continued each quarter to overstate revenue by recognizing sham sales, improper bill-and-hold sales, sales with contingent terms, and sales without fixed commitment or price. Most of these improper practices were carried out at the end of each quarter.

Next, we illustrate how auditors may use the evidential network to assess fraud risk through assessing the presence of fraud triangle factors. We then discuss how this assessment could be used to further plan the audit, to collect and aggregate audit evidence, and to assess the risk that material fraud has been committed. Figure 2 (Step 1) presents the evidential diagram for the fraud risk assessment based on the assessment of the presence of incentives, attitude, and opportunities to commit fraud in the revenue account of FLIR based on the model developed by [36]. The main assertion "Fraudulent Revenue" in Figure 2 is logically connected with the sub-assertions through an $A N D$ relationship because for fraud to occur, there must be Incentive, Attitude and Opportunity.

In the analysis we assume that evidence designated 'E.Prior' in Figure 2 (Step 1) is available from client acceptance analysis and results in an assessment of the belief that fraud is not present as 0.95 and the plausibility of fraud to be less than or equal to 0.05 . We further assume that the prior belief in fraud equals 0.00 . These assumptions are indicated in Figure 2 
(Step 1) as a prior of $(0.0,0.95)$. The belief masses from the other nine items of evidence pertaining to the corresponding variables are given in the respective items of evidence. The first number represents the belief that the variable is true and the second number the belief that it is not true. These belief masses are assumed judgment based on the details available from the SEC description of the FLIR [39-41].

For example, we use the following information to assess the presence of incentives to commit fraud. Throughout 1998 and 1999, FLIR's senior management had established budgets that projected growth in FLIR's results. The company's actual earnings per share in 1998 generally met or exceeded analysts' estimates, but revenues did not [40]. Also, FLIR acquired AGEMA Infrared Systems in December 1997 and merged with Inframetrics, Inc. in March 1999. Both mergers exacerbated the pressure on management to achieve financial goals. Although these factors are certainly not evidence of fraud, they are risk factors that indicate incentives for management to commit fraud. We use the above evidence pertaining to the fraud triangle factor "incentive" and assess the strength of the evidence to be 0.05 for the evidence of pressures from mergers, represented by E.T.2 in Figure 2 (Step 1); and 0.1 for the evidence of earnings projection target and the evidence of annual bonus based on pre-tax profit, represented by E.T.1 and E.T.3 respectively in Figure 2 (Step 1). Details on the remaining risk factors and the analysis of results from analytical procedures is available from the authors.

All of the strength of evidence assessments (mvalues) including the prior belief of 0.95 that fraud was not present in the account are aggregated and propagated within the network. As Figure 2 (Step 1) shows, the updated assessment of belief that fraud is present in the revenue accounts is $\operatorname{Bel}($ fraud) $=0.049$ and the belief that fraud is not present is 0.903 . This implies that unassigned belief (the level of ambiguity) is 0.048 . Thus the plausibility of fraud is assessed to be 0.097 . Thus the combination of some fraud triangle risk factors and some analytical procedures has resulted in a 'posterior' fraud risk assessment that should be of concern to the audit team as it exceeds the 0.05 threshold. Given this assessment, the audit team must then decide what to do next? The key decisions include deciding what additional audit procedures need to be conducted? As will be seen, the framework sketched in Figure 1 facilitates this assessment greatly.

Figure 2 (Step 2) represents the updated assessment of beliefs considering specific account schemes. If the preliminary assessment of fraud risk is at all significant, the auditor should then evaluate how management could have perpetrated fraud [2]. Figure 2 (Step 2) lists several examples of account schemes that have been used in previous fraud cases as disclosed in SEC releases [41-43]. The account schemes are classified into general schemes and specific schemes, and the subassertions of specific schemes are connected through the "Conditional $O R$ " $(C R)$ relationship to the assertions of general schemes.

The parameters of the $C R$ relationships are based on the frequency of the revenue fraud cases as described in the SEC AAERs issued from 1997 to 2002. Because of space limitations, details of these relationships are not provided. However, readers can obtain the details from the authors. In general, the audit team would have several other specific fraud schemes to consider, but to make the illustration simple, we have merged some of these specific schemes into broader schemes.

During the process of understanding FLIR's business and the preliminary assessment of fraud risk, the auditor may notice some characteristics of FLIR that could indicate the presence of certain types of fraud schemes. For example, as described in FLIR's 1998 annual report, 17.7 percent of FLIR's revenue was derived from sales to agencies of the U.S. government. Some of these sales were contingent. This piece of evidence suggests a company that is able to prematurely recognize revenue. We assess the strength of this evidence, E.AS.1 in Figure 2 (Step 2) to be at a low level, say 0.1 , to support the assertion of contingent sales.

Throughout 1998, FLIR engaged in a significant number of bill-and-hold sales, which could indicate a risk of improperly recognized bill-and-hold sales. We assess the strength of this evidence (E.AS.2) to be 0.1 .

Lastly, compared to 1996 and 1997, FLIR had a continuous increase in its inventory turnover rate during 1998, particularly during the third and fourth quarters indicating that the inventory holding period was shortened in 1998. This indicates a risk of fraud scheme related to incomplete inventories. At the same time, FLIR had a relatively stable accounts receivable turnover rate. In other words, although inventory moved faster, the cash collection from sales was not improving. Both ratios then dropped dramatically in the first quarter of 1999. We assess the abnormal increase in the inventory turnover as a risk factor, represented by E.AP.4, providing support to the assertion of premature revenue recognition. The strength is assessed to be 0.05 .

After aggregating and propagating the beliefs from the main assertion to the sub-assertions of account schemes, we observe from Figure 2 (Step 2) that the updated plausibility of fraud is 0.124 with belief in fraud being 0.076 . Further, the evidence suggests that the client is most likely to have committed fraud using "premature revenue recognition", with belief of 0.054 , and in particular using premature revenue recognition on contingent sales, with belief of 0.032 . Our framework shows that the auditor should first perform audit procedures to evaluate whether premature revenue recognition has actually occurred

Figure 3 (Step 3) represents the final step in assessing fraud risk where we consider the evidence specific to account schemes and evidence schemes. To improve audit effectiveness and efficiency when planning audit procedures and audit programs, it would seem prudent to focus on testing those assertions where there is the highest belief in fraud. Performing the kinds of assessments suggested using our framework has the advantage of providing rigorous, quantitative risk assessments. As for the audit of FLIR, the analysis implies that the auditor should have first assigned more effort to collect and 
evaluate evidence as to whether the company had recognized revenues prematurely, especially whether the company had recognized contingent sales improperly.

When committing fraud, management often uses evidence schemes to deceive auditors and conceal fraud. Therefore, when belief in fraud is assessed to be high, the auditor should not only perform regular procedures but also procedures for the special purpose of detecting evidence-based fraud schemes. Figure 3 integrates assertions of specific evidence schemes into the evidential diagram, and such assertions are connected to the assertion of revenue recognition on contingent sales through the $C R$ relationship.

When deciding on the nature of audit tests, auditors should select those procedures that are relatively more effective in detecting fraudulent activities related to high-risk assertions and those that can be effective in detecting multiple schemes. As indicated in Figure 3, study of previous fraud cases indicates that clients are most likely (61 percent) to hide side letters or agreements with customers from auditors to conceal the fraud, with collusion with customers and others occurring 31 percent of the time and forging of documents 8 percent. Therefore, the planning of audit programs should focus on those procedures that may be effective in detecting hidden side letters, then on those procedures that may be effective in detecting collusions between client and its customers.

For illustrative purposes, we select several procedures from a list of procedures that were ranked by auditors to be effective in detecting high-risk fraud schemes. The effectiveness of these procedures was evaluated by the two experienced auditors, a manager with 9 years of audit experience and a senior with 4 years of audit experience.

In Figure 3, the selected procedures are depicted by the rectangular boxes on the right hand side. The assumed level of support for various assertions is given inside of the evidence boxes. This judgment is based on the assumption that after performing these audit procedures, the auditor has evaluated the evidence and assessed the beliefs regarding the related assertions in the evidential diagram.

The first procedure given in Figure 3 is sending confirmations to customers, a standard audit procedure that provides evidence concerning multiple assertions. This is a procedure that may help detect the evidence schemes of using forged documents and of hiding side letters from auditors.

This procedure was used by FLIR's auditor to confirm accounts receivable $(\mathrm{A} / \mathrm{R})$ balances. But, the sales representative who was involved in a $\$ 4.1$ million sales transaction which was prematurely recognized by FLIR and also was involved in the sham shipments of the incomplete units refused to return the confirmation. Such a non-response from a customer should have signaled the auditor that the sale might have been fraudulent or there could be some disagreements on the amounts or terms of the sale. As shown in Figure 3, we assess the strength of the evidence represented by E.ES. 1 to only be 0.4 that related assertions are true.
After assessing the collected evidence with regard to the related assertions as depicted in Figure 3 and aggregating the assumed belief values, the updated belief in fraudulent revenue increases to 0.386 , clearly a high level of belief and a plausibility of 0.418 that fraud may have occurred. Although just illustrative, the incorporation of all of the evidence impounded in Figure 3 and in prior figures implies that the auditor of FLIR was on tenuous grounds in expressing an unqualified opinion on the FLIR's 1998 financial statements. This conclusion is, of course, consistent with the results of SEC investigation.

Our framework suggests that an appropriate step in assessing fraud risk is to take into account how fraud may have been perpetrated and concealed. To accomplish this, the audit team would need to incorporate evidence related to the kinds of evidence schemes that typically are used and propagate this evidence throughout the evidential network as sketched in Figure 1. The analysis results in the assessments of belief masses as depicted in Figure 3 (Step 3). Specifically, the belief that there is fraud in the revenue accounts is now 0.386 and the plausibility of fraud has now risen to 0.418 . Clearly the audit team should be very concerned!

In addition to providing numerical assessments of fraud risk based on the rigor of belief function updating, the framework provides some important information on which schemes the client may have used to perpetrate fraud. This knowledge should help direct the auditor to tests that are most likely to be effective and to a more efficient audit. In the case of FLIR, given the assumptions we have used as to strength of evidence, the audit team likely would benefit most from first investigating hidden sales agreements (ES.1), then forged sales documents (ES.3) and finally collusion with customers or third parties. In fact, these assessments in the FLIR setting suggest that it is likely that the management may have used all three evidence schemes to perpetrate fraud which, in fact, was the actual situation.

\section{Summary and conclusion}

This paper presents and illustrates a framework to assess fraud risk and belief in fraud by integrating fraud risk triangle factors, account-based fraud schemes and evidence-based fraud schemes using an evidential reasoning approach based on DS theory. The framework extends prior models for assessing fraud risk and the belief in fraud by integrating fraud schemes and fraud frequency information based on previous fraud cases disclosed by the SEC. Additional private fraud information available within each audit firm can be added to the SEC information to potentially improve the audit process even more. Importantly, the framework provides a structured approach for building connections between risk assessment, audit program planning, and evaluation of results.

The approach is illustrated using a real fraud case which involves preliminary fraud risk assessments, 
audit program planning, evidence aggregation and evaluation, and a final fraud risk assessment. As expected, the analysis shows that to improve the efficiency of fraud detection, auditors should emphasize audit procedures that are known to be effective in detecting high-risk fraud schemes.

Our analysis shows that the overall belief in fraud increases significantly when specific account schemes are incorporated and corresponding items of evidence are aggregated. Furthermore, when specific evidence schemes are incorporated into the evidential diagram and the corresponding items of evidence are assessed and aggregated, the overall belief in fraud increases significantly from 0.076 to 0.386 , suggesting with a high degree of belief that fraud is present in the reported revenue of FLIR. A similar increase in the plausibility of fraud is also shown.

As the first attempt to integrate fraud triangle factors, account fraud schemes and evidence fraud schemes into the assessment of fraud risk, the suggested framework is still at a conceptual level and exhibits several limitations. For example, being based on a relatively novel theory, the Theory of Belief Functions, may lead to challenges in gaining academic acceptance. Also, any scoring scheme you put in place may provide opportunities and incentives for gaming the system.

The proposed framework also suggests future research needs. For example, its performance should be subject to further examinations in additional fraud cases, in experiments and in practice and in comparisons with other approaches to fraud risk assessment such as expert systems and neural networks. Also, empirical studies could research the frequency information integrated into the fraud risk assessment model as to data limitations, such as disclosure bias, which may affect the accuracy of fraud risk assessment. As suggested earlier, audit firms should modify the proposed framework by incorporating their firmspecific experience and knowledge of fraud and of each particular client. Additional analytical research could utilize a theorem prover or a model checker to assess additional framework attributes.

Lastly, our approach provides the audit team with assessments of both belief in fraud and plausibility of fraud. While plausibility in fraud assesses the worst scenario case that fraud could be present, the belief in fraud which is based on the direct evidence can trigger further investigations to detect fraud [45]. Thus, both measures of risk are important; $\mathrm{Pl}($ fraud) measures the maximum risk and Bel(fraud) triggers further investigation.

\section{References}

[1] American Institute of Certified Public Accountants. Consideration of Fraud in a Financial Statement Audit. Statement on Auditing Standards. No. 82. New York, NY, 1997.

[2] American Institute of Certified Public Accountants. Consideration of Fraud in a Financial Statement Audit. Statement on Auditing Standards. No. 99. New York, NY, 2002.
[3] S.K. Asare, and A. Wright, "The effectiveness of alternative risk assessment and program planning tools in a fraud setting", Contemporary Accounting Research (Summer): 2004, 325-352.

[4] J.C. Bedard, T.J. Mock, and A.M. Wright, "Evidential planning in auditing: A review of the empirical research", Journal of Accounting Literature, 18, 1999, 96-142.

[5] T.B. Bell, and J.V. Carcello, "A decision aid for assessing the likelihood of fraudulent financial reporting", Auditing: A Journal of Practice \& Theory (Supplement), 2000, 68-84.

[6] R.J. Bloomfield, "Strategic dependence and the assessment of fraud risk: A laboratory study", The Accounting Review, October, 1997, 517-538.

[7] S.P. Curley, and J.I. Golden, "Using belief functions to represent degrees of belief", Organizational Behavior and Human Decision Processes, 58, 1994, 271-303.

[8] M.M. Eining, D.R. Jones, and J.K. Loebbecke, "Reliance on decision aids: An examination of auditors' assessment of management fraud", Auditing: A Journal of Practice \& Theory, Fall, 1997, 1-19.

[9] B. Fischhoff, P. Slovik, and S. Lichtenstein, "Fault trees: sensitivity of estimated failure probabilities to problem representation", Journal of Experimental Psychology: Human Perception and Performance, 4, 1978, 330-344.

[10] L. Gao, "Investigation of the perpetration and concealment process of management fraud: An empirical analysis of fraud schemes" Unpublished Dissertation, University of Kansas, 2005.

[11] L. Gao, and R. P. Srivastava, "The anatomy of management fraud schemes: Analyses and implications", Working Paper, University of Nebraska-Lincoln, 2009.

[12] S. Grazioli, K. Jamal, and P.E. Johnson, "A cognitive approach to fraud detection", Working Paper, University of Virginia, 2008.

[13] B.P. Green, and H.H. Choi, "Assessing the risk of management fraud through neural network technology", Auditing: A Journal of Practice \& Theory, Spring, 1997, 1428 .

[14] K. Harrison, R.P. Srivastava, and R.D. Plumlee, "Auditors' evaluations of uncertain audit evidence: Belief functions versus probabilities. Belief Functions in Business Decisions", edited by R.P. Srivastava and T. Mock, PhysicaVerlag, Heidelberg, Springer-Verlag Co, 2002, 161-183.

[15] V.B. Hoffman, and M.F. Zimbelman, "Do strategic reasoning and brainstorming help auditors change their standard audit procedures in response to fraud risk?" Working Paper, University of Pittsburgh, 2008.

[16] J.D. Lowrance, T.D. Garvey, and T.M. Strat, "A Framework for Evidential-Reasoning Systems", AAAI-86 Proceedings, 1986

[17] E.M. Matsumura, and R. Tucker, "Fraud detection: A theoretical foundation", The Accounting Review, October, 1992, 753-782. 
[18] T. Mock, L. Sun, R.P. Srivastava, and M. Vasarhelyi, "An Evidential Reasoning Approach to Sarbanes-Oxley Mandated Internal Control Risk Assessment under DempsterShafer Theory", International Journal of Accounting Information Systems, Volume 10, Number 2, 2009, 65-78

[19] T.J. Mock, and J.L. Turner, An archival study of audit fraud risk assessments following the issuance of SAS No. 82. Special Report to the Auditing Standards Board of the AICPA, 2001.

[20] M.W. Nelson, J.A. Elliott, and R.L. Tarpley, "How are earnings managed? Examples from Auditors", Accounting Horizons, Supplement, 2003, 17-35.

[21] E. Patterson, and J. Noel, "Audit strategies and multiple fraud opportunities of misreporting and defalcation", Contemporary Accounting Research, Fall, 2003, 519-549.

[22] J. Pearl, "Bayesian and Belief-Functions formalism for evidential reasoning: A conceptual Analysis. Readings in Uncertain Reasoning, CA: Morgan Kaufmann Publishers, Inc., 1990, 540-574.

[23] K. Pincus, "The efficacy of a red flags questionnaire for assessing the possibility of fraud", Accounting, Organizations and Society, 14, 1989, 153-163.

[24] Public Company Accounting Oversight Board. 2007. Observations on Auditors' Implementation of PCAOB Standards Relating to Auditors' Responsibilities with Respect to Fraud. Release No. 2007-01, Washington D.C., January 2007.

[25] G. Shafer, A Mathematical Theory of Evidence. Princeton University Press, 1976.

[26] G. Shafer, and R.P. Srivastava, "The Bayesian and Belief-Function formalisms: A general perspective for auditing. Auditing", A Journal of Practice and Theory, Supplement, 1990, 110-148.

[27] P. Shenoy, and G. Shafer, "Axioms for probability and Belief-Function propagation", Uncertainty in Artificial Intelligence 4, edited by R.D. Shachter et al. Amsterdam, North-Holland, 1990, 169-198.

[28] P. Smets, "The transferable belief model for quantified belief representation", Quantified Representation for Uncertainty and Imprecision, Vol. 1. Edited by P. Smets. Kluwer Academic Publishers, 1998.

[29] R.P. Srivastava, "Belief functions and audit decisions", Auditor's Report, Vol. 17, No. 1, Fall, 1993, 8-12.

[30] R.P. Srivastava, "The Belief-Function Approach to Aggregating Audit Evidence", International Journal of Intelligent Systems, Vol. 10, No. 3, March, 1995, 329-356.

[31] R.P. Srivastava, S. K. Dutta, and R. Johns, "An Expert System Approach to Audit Planning and Evaluation in the Belief-Function Framework" International Journal of Intelligent Systems in Accounting, Finance and Management, Vol. 5, No. 3, 1996, 165-183.

[32] R.P. Srivastava, L. Gao, and P. Gillett, "Representation of Interrelationships among Binary Variables under
Dempster-Shafer Theory of Belief Functions" International Journal of Intelligent Systems, Volume 24, Issue 4, 2009, $459-475$

[33] R.P. Srivastava, and T.J. Mock, "Why we should consider belief functions in audit research and practice", The Auditor's Report, Vol. 28, No. 2, March, 2005.

[34] R.P. Srivastava, and T.J. Mock, "Evidential Reasoning for WebTrust Assurance Services", Journal of Management Information Systems, Vol. 16, No. 3, Winter, 2000, 11-32.

[35] R.P. Srivastava, T. Mock, and J. Turner, "Analytical formulas for risk assessment for a class of problems where risk depends on three interrelated variables", International Journal of Approximate Reasoning Vol. 45, 2007, 123-151.

[36] R.P. Srivastava, T. Mock, and J. Turner, "Bayesian fraud risk formula for financial statement audits", Abacus, March, 2009, 66-87.

[37] R.P. Srivastava, and G. Shafer, "Belief-Function formulas for audit risk", The Accounting Review, April, 1992, 249-283.

[38] L. Sun, R.P. Srivastava, and T. Mock, “An information systems security risk assessment model under DempsterShafer theory of belief functions", Journal of Management Information Systems, Vol. 22, No. 4, 2006, 109-142.

[39] The Securities and Exchange Commission, Accounting and Auditing Enforcement Releases No. 1637. In the matter of FLIR Systems, Inc, 2002.

http://www.sec.gov/litigation/admin/33-8135.htm.

[40] The Securities and Exchange Commission, Accounting and Auditing Enforcement Releases No. 1639. SEC charges former management of FLIR Systems, Inc. with scheme to inflate revenue, 2002.

http://www.sec.gov/litigation/litreleases/lr17760.htm

[41] The Securities and Exchange Commission, Accounting and Auditing Enforcement Releases No. 1649. In the matter of J. Mark Samper, CPA, 2002.

http:/www.sec.gov/litigation/admin/34-46634.htm

[42] The Securities and Exchange Commission, Accounting and Auditing Enforcement Releases No. 1670. In the matter of James A. Fitzhenry, 2002.

http://www.sec.gov/litigation/admin/34-46870.htm

[43] T.J. Wilks, and M.F. Zimbelman, "Using game theory and strategies reasoning concepts to prevent and detect fraud." Accounting Horizon, September, 2004, 173-184.

[44] J. Yang, D. Xu, X. Xie, and A.K. Maddulapalli, "Evidence Theory and Multiple Criteria Decision Analysis: The Evidential Reasoning Approach", Proceedings of The 2010 Workshop on the Theory of Belief Functions, Brest, France, April 1-2.

[45] H. Fukukawa and T. J. Mock. "Audit Risk Assessments Using Belief versus Probability". Auditing: A Journal of Practice \& Theory. 2010 (forthcoming). 
Figure 1: The General Evidential Diagram for Assessing Belief in Fraud and Plausibility of Fraud

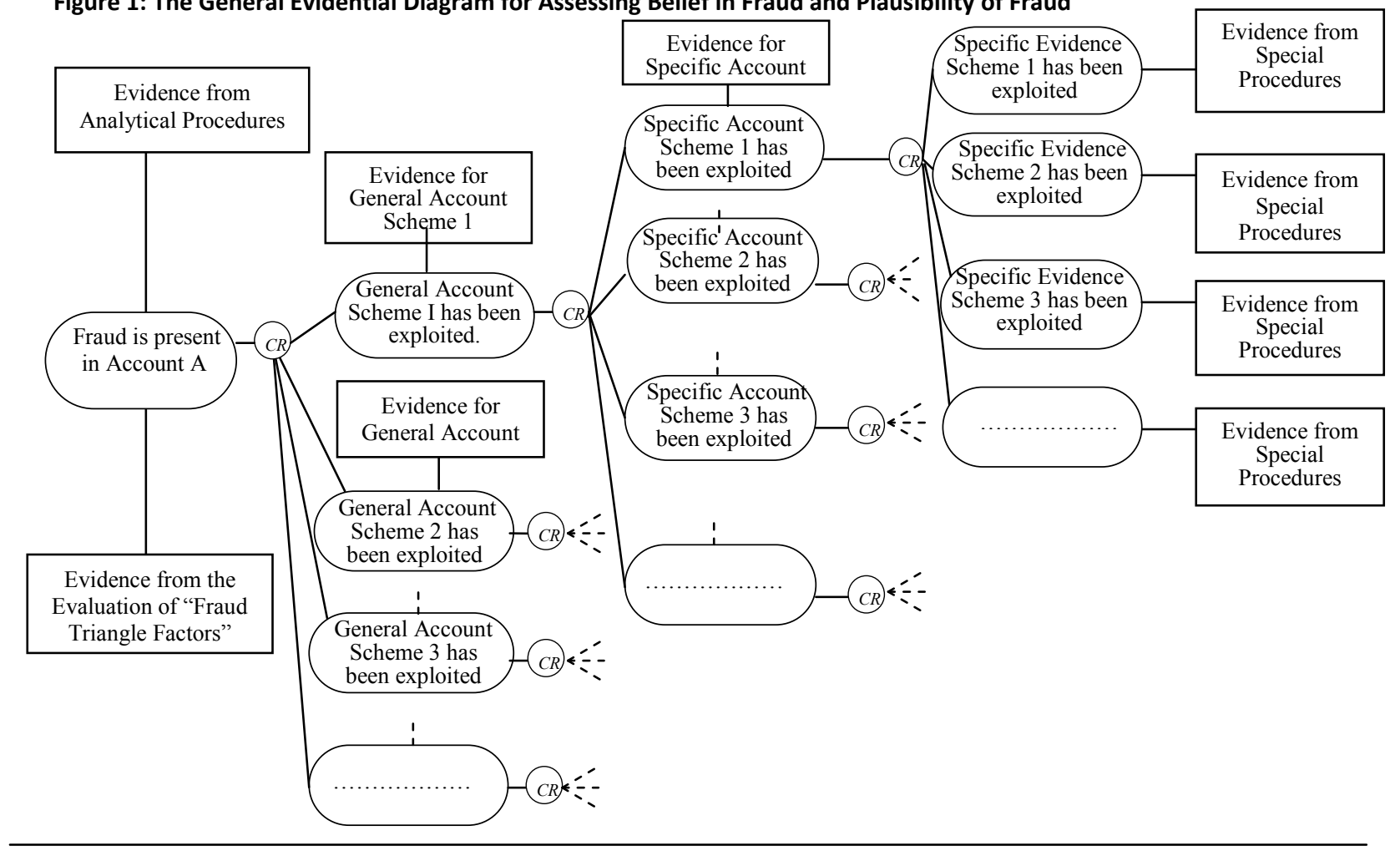

Figure 2 (Step 1): Updating Client Acceptance: Assessment of Belief in Fraud and Plausibility of Fraud in Revenues ${ }^{\mathrm{a}}$

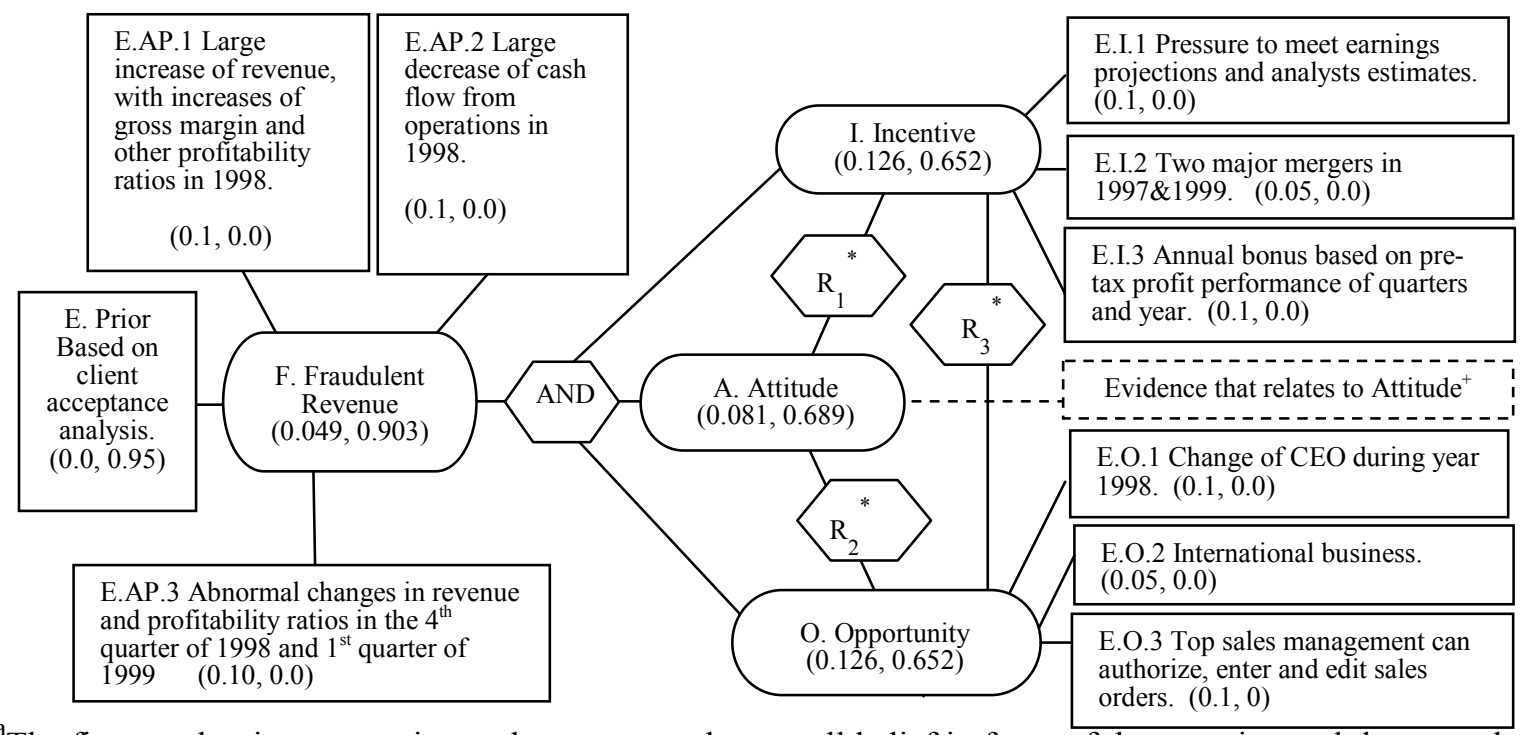

${ }^{\mathrm{a}}$ The first number in an assertion node represents the overall belief in favor of the assertion and the second number represents the belief against the assertion. The first number in an evidence node represents the strength of the evidence in support of the assertion node(s) it is connected to and the second number represents the belief in support of the negation of the assertion(s).

* The values of $R_{1}, R_{2}, R_{3}$ are assumed to be at a medium level, say 0.7 , in this paper. This means when one fraud triangle factor (e.g., incentive) is assessed to be present, the related assertions (e.g., attitude and opportunity) will have a 70 percent chance of being present.

${ }^{+}$No evidence related to attitude of management towards fraud was found in the FLIR Systems, Inc case. The evidence node is listed here to remind the auditor that he/she should collect and evaluate evidence that may indicate management's attitude of committing fraud when such risk factors are evident. 


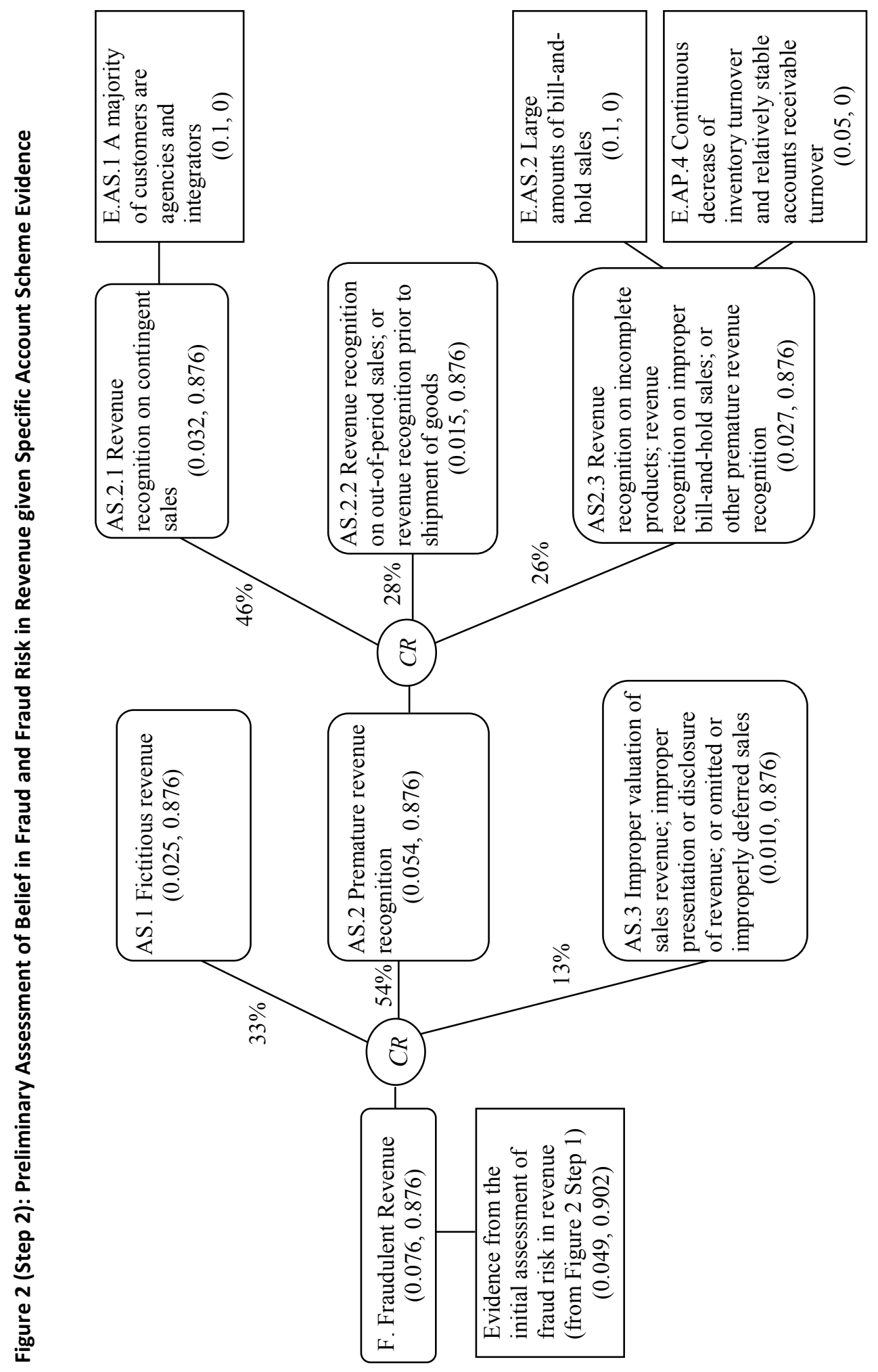




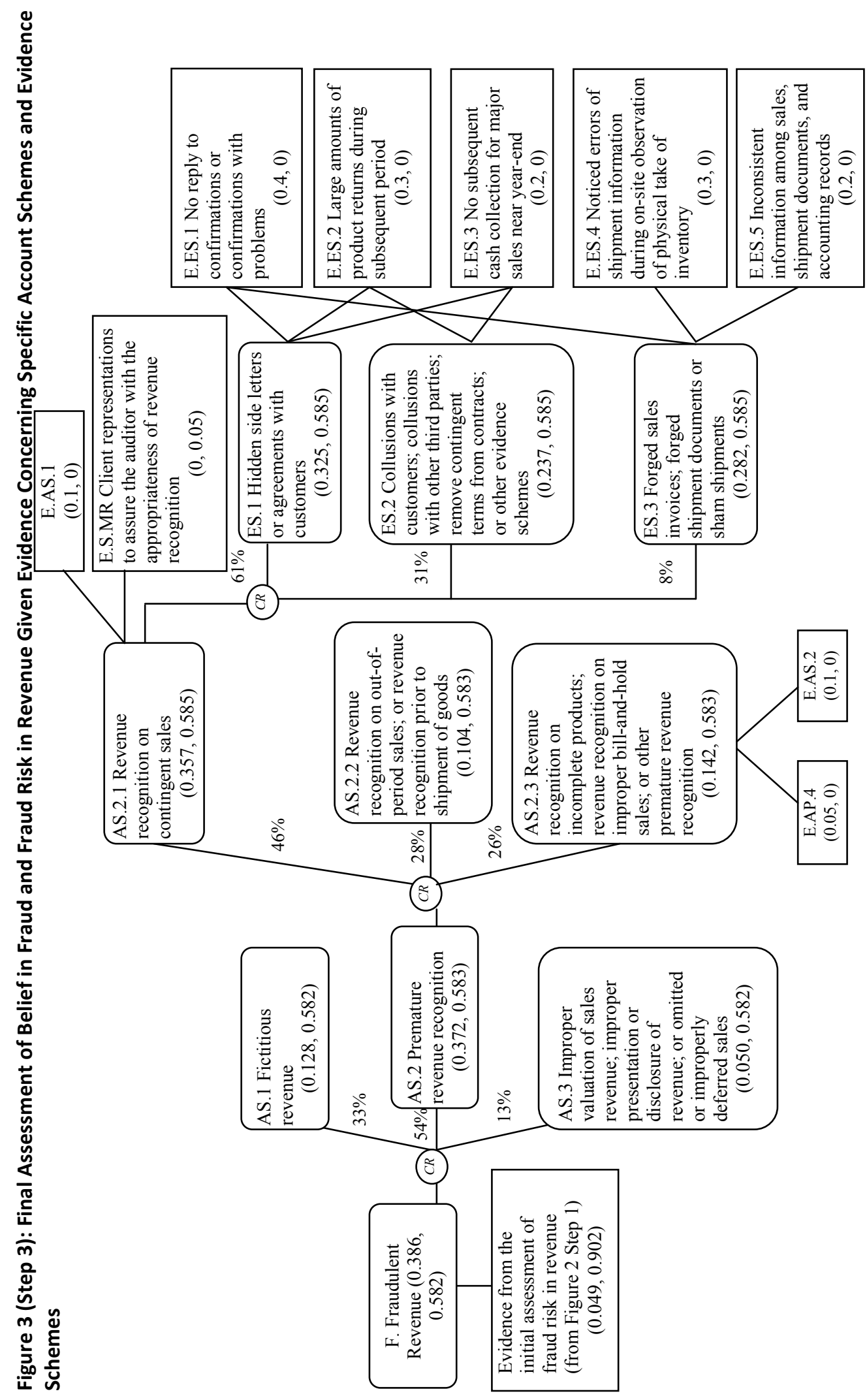

